\title{
Direct Real Time Microstructure Evolution Observation of Ti-6Al-4V Alloy by In- Situ EBSD during Cycling Heating and Cooling at Elevated Temperatures using $\mu$ heater in SEM/FIB Systems
}

\author{
Min Wu, Libor Novák
}

Thermo Fisher Scientific, Materials \& Structural Analysis, Brno, Czech Republic

As the most widely applied industrial materials in aerospace and medicine fields, titanium alloy Ti-6Al$4 \mathrm{~V}$ has drawn ongoing research interests regarding the control and optimization of its microstructure in order to achieve desired properties. Numerous experimental and modelling efforts have been made to understand the microstructures, phases and phase transformation mechanism in this dual phase alloy in the past decades[1]. However, none of the previous work has achieved direct real time observation of the microstructure evolution of Ti-6Al-4V alloy at desired elevated temperatures (above $\beta$ transus temperature approximately $995^{\circ} \mathrm{C}$ ) due to technical limitations. Nevertheless, state-of-the-art microelectromechanical system (MEMS)-based micro heating device ( $\mu$ Heater) brings unique opportunities for convenient, fast and reliable in-situ heating (rapid heating/cooling rate in the order of $10^{4} \mathrm{~K}$ per second up to $1200^{\circ} \mathrm{C}$ ) under high vacuum conditions in $\mathrm{SEM} / \mathrm{FIB}$ systems[2] and is compatible with all types of detectors such as EBSD, EDS and STEM[3].

In this contribution we present a comprehensive study of in-situ EBSD characterizations on deformed dual phase $(\alpha+\beta)$ Ti-6Al-4V alloy during cycling heating and cooling treatments between $850^{\circ} \mathrm{C}$ and $1200^{\circ} \mathrm{C}$ using $\mu$ Heater in a ThermoFisher Scientific DualBeam ${ }^{\mathrm{TM}}$ SEM/FIB Helios ${ }^{\mathrm{TM}}$ G4 work station equipped with a standard EBSD detector. Chunk sample of size 50x40x20 $\mu \mathrm{m}^{3}$ was fabricated using FIB milling from the bulk, subsequently in-situ lifted out and welded onto the MEMS chip by an in-chamber micromanipulator (see Figure 1). The sample surface was then cleaned on the MEMS chip with low energy ion to improve EBSD pattern quality. The metallic chunk was first heated at a rate of $10^{3} \mathrm{~K}$ per second to $850^{\circ} \mathrm{C}$, subsequently treated in a cycling heating and cooling process between $850^{\circ} \mathrm{C}$ and $1200^{\circ} \mathrm{C}$ using the same heating rate. In-situ EBSD maps were acquired at room temperature and during each isothermal annealing step. The average hit rate (indexing percentage) for the maps are above $95 \%$ and did not decrease during the heating. It is also shown that high quality EBSD patterns can be collected even at $1200^{\circ} \mathrm{C}$ attributing to the small thermal mass of the $\mu$ Heater. Real time microstructure evolution such as dynamic recrystallization, grain boundary migration (see Figure 2) and phase transformation $(\mathrm{Ti} \alpha<->\beta$ ) (see Figure 3) was observed during the continuous heat treatment sequence. All analytical work was conducted at $20 \mathrm{kV}$ and $11 \mathrm{nA}$ with a step size of $300 \mathrm{~nm}$. In addition, bulk microstructures of both the as-received and post mortem state have been investigated by extracting TEM lamellae from the chunk sample and checking with STEM-in-SEM technique in the same work station.

\section{References:}

[1]C. Kenel et al., Sci. Rep. 7 (2017), p. 1.

[2]L. Mele et al., Microsc. Res. Tech. 79 (2016), p. 239.

[3]L. Novák et al, Microsc. Microanal., 23 S1 (2017), p. 928. 

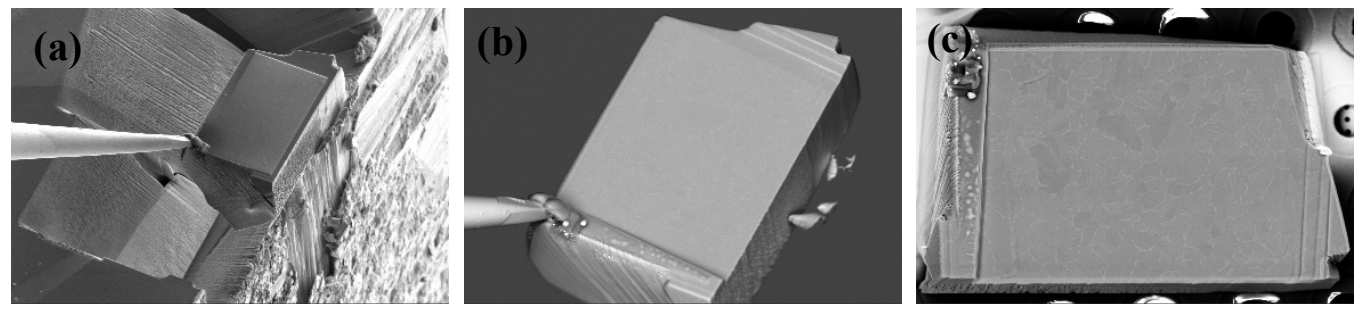

Figure 1. The Ti-6Al-4V chunk sample (a) fabricated in bulk and in-situ lifted out by FEI 'Easylift' micromanipulator, (b) surface polished and (c) attached to a MEMS heating chip. The chunk surface size is $50 \mu \mathrm{m} \times 40 \mu \mathrm{m}$.

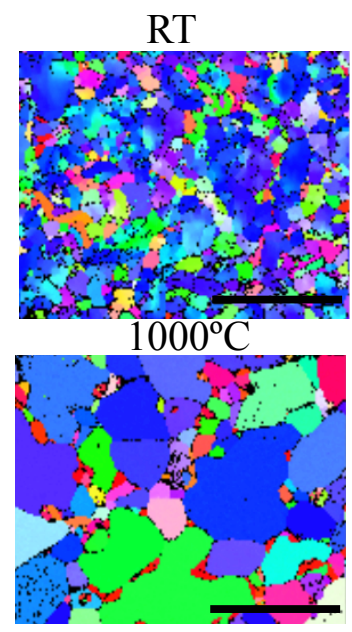

$1170^{\circ} \mathrm{C}$
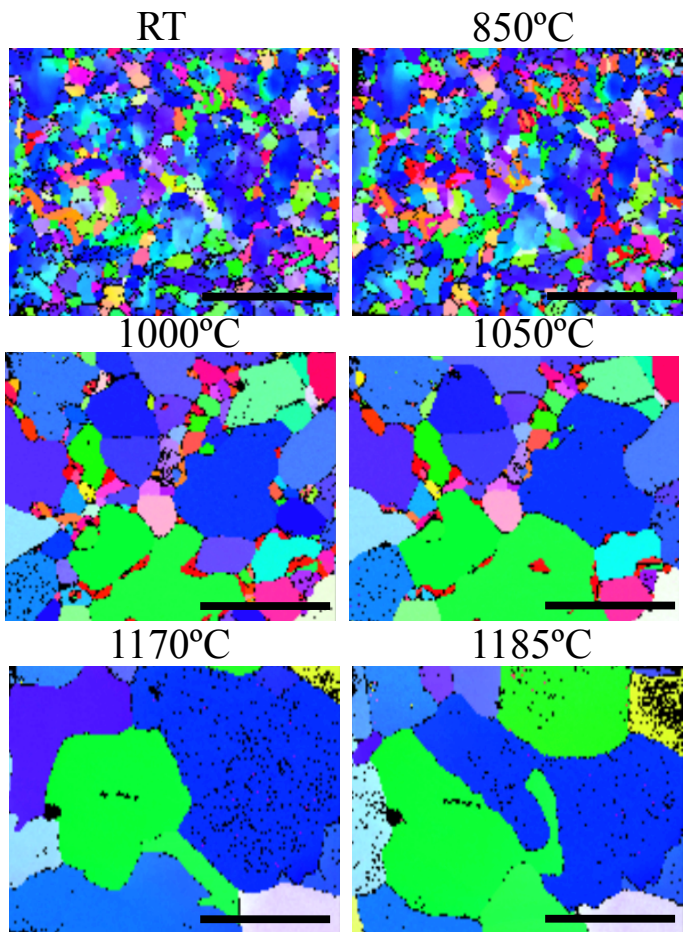

$1050^{\circ} \mathrm{C}$

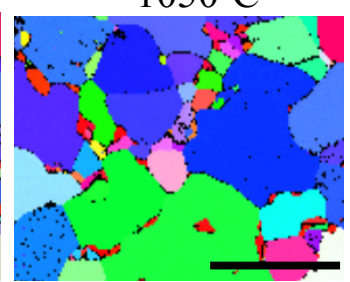

$1185^{\circ} \mathrm{C}$

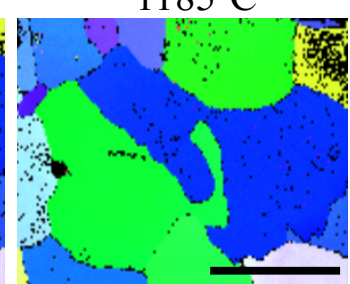

$900^{\circ} \mathrm{C}$

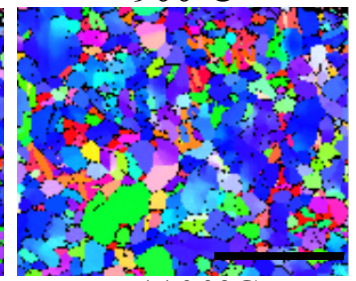

$1100^{\circ} \mathrm{C}$
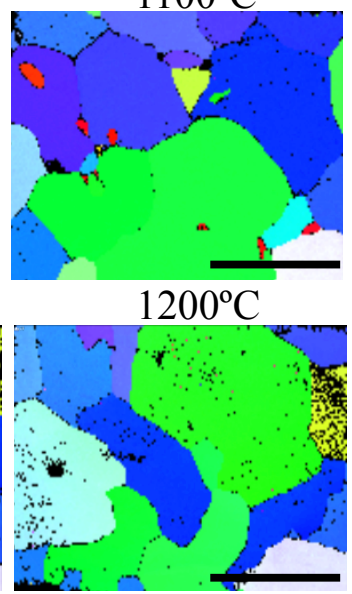
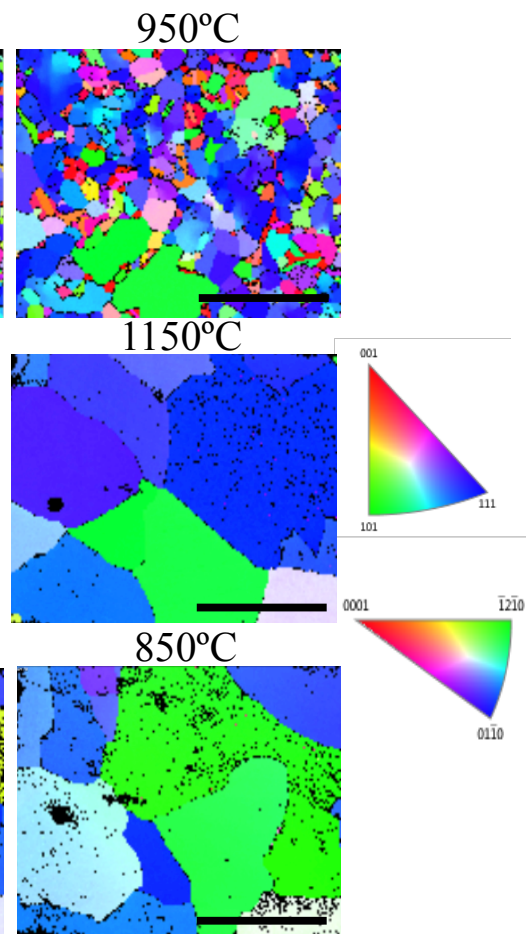

Figure 2. Original EBSD inversed pole figure maps of Ti-6Al-4V alloy collected at room temperature and at each isothermal step during the heating and cooling cycle. Scale bar in each map is $20 \mu \mathrm{m}$. Each map was acquired in approximately 7 minutes. Sequential IPFZ maps show a distinct recrystallization and grain growth process at elevated temperatures.
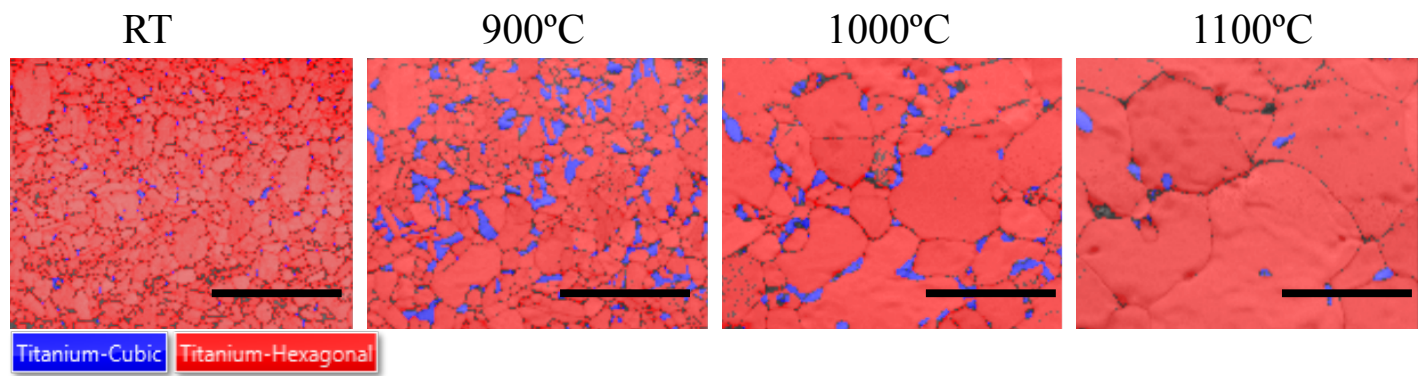

Figure 3. Overlayed phase maps with band contrast maps of Ti-6Al-4V alloy acquired at room temperature, $900^{\circ} \mathrm{C}, 1000^{\circ} \mathrm{C}$ and $1100^{\circ} \mathrm{C}$ show a transformation cycle from initial Ti- $\alpha$ (hcp) to Ti- $\beta$ (bcc) to final Ti- $\alpha(\mathrm{hcp})$ in the in-situ heating sequence. Scale bar in each map is $20 \mu \mathrm{m}$. 